Source: Heravi, M.M., Rezvanian, A., Shaabani, Z., Tajbakhsh, M. (2017), Five-component synthesis of dihydropyridines based on diketene, Journal of Tetrahedron, 73(15), doi: 10.1016/j.jorganchem.2018.05.018

\title{
Five-component synthesis of dihydropyridines based on diketene
}

\author{
Majid M. Heravi ${ }^{1}$, Atieh Rezvanian ${ }^{1}$, Zahra Shaabani $^{1}$, Mahmood Tajbakhsh ${ }^{2}$ \\ ${ }^{1}$ Department of Chemistry, Faculty of Physics \&Chemistry Alzahra University, Vanak, Tehran, Iran. \\ ${ }^{2}$ Faculty of Chemistry, University of Mazandaran, Babolsar, Iran.
}

\begin{abstract}
A novel five-component strategy involving commercially available diketene, primary amines, malononitrile and various benzaldehydes for the synthesis of densely functionalized 1,4-dihydropyridines in good yields was achieved. The reaction pathway involves a sequential ring-opening of diketene/enamine formation/Knoevenagel-condensation/Michael addition and 6-exo-tet cyclization, resulting in multiple bond-formation events including two $\mathrm{C}-\mathrm{C}$ and three $\mathrm{C}-\mathrm{N}$ bonds ultimately leading to the formation of the respective 1,4dihydropyridines.
\end{abstract}

\section{Keywords}

1,4-dihydropyridines, Diketene, Five-component reaction, Primary amine, 1,4 dihydropyridine derivative, enamine, unclassified drug, Article, chemical structure, covalent bond, cyclization, drug mixture, ring opening, Synthesis, Knoevenagel condensation, Michael addition, one pot synthesis, priority journal, reaction analysis, drug 